\title{
Limnologia e sua Correlação com a Produtividade da Tilápia Oreochromis niloticus
}

\author{
Djair Alves da Mata ${ }^{1}$, Tancredo Souza ${ }^{1 *}$, Cássio Macêdo Gomes ${ }^{1}$, Rayane Amaral De Andrade ${ }^{1}$, Marisa de \\ Oliveira Apolinário ${ }^{2}$
}

\begin{abstract}
RESUMO: Esse estudo propõe a exploração de novos horizontes no que diz respeito à piscicultura. Nesse contexto, foi desenvolvida uma pesquisa na propriedade rural Sítio Gurjaú, localizada no município de Coronel Ezequiel - RN, no período de agosto de 2016 a julho de 2017. O presente estudo teve como objetivos avaliar os parâmetros físicos e químicos da água em tanques escavados e o reflexo que estas variáveis exercem sobre o desempenho produtivo da tilápia Oreochromis niloticus (Linhagem Chitralada). Sendo assim, ocorreram visitas quinzenais, sendo possível coletar água e submetê-las a estudos físicos e químicos por meio do Kit Acqua Supre, oxímetro e disco de Secchi, sendo estas variáveis: temperatura, transparência, alcalinidade, dureza, oxigênio dissolvido (OD), amônia total, nitrito, gás carbônico, e potencial hidrogeniônico $(\mathrm{pH})$. Os dados aferidos foram submetidos à estatística descritiva, permitindo observar a média dos valores correspondentes. Resultados relacionados aos parâmetros hidrológicos, como OD na água alcançaram valores entre 6,92 a 9,63 mg/L; gás carbônico dissolvido na água com uma média de 17,02 mg/L; nitrito, correspondo a média de $0,2 \mathrm{mg} / \mathrm{L}$ e amônia total, com média de $2,09 \mathrm{mg} / \mathrm{L}$. Esse estudo tem importância econômica na exploração da tilapicultura como alternativa, abrindo possibilidade para a sustentabilidade e o agronegócio.
\end{abstract}

Palavras-chave: piscicultura, tanque escavado, parâmetros hidrológicos

\section{Limnology and your Correlation with Productivity of Tilapia Oreochromis niloticus}

\begin{abstract}
This study proposes to explore new horizons with regard to fish farming. In this context, a survey on rural property Sítio Gurjaú, located in the municipality of Coronel Ezequiel - RN, in the period of August 2016 the July 2017. The present study aimed to evaluate the physical and chemical parameters of water in tanks dug and the reflection that these variables exert on the productive performance of Tilapia Oreochromis niloticus (Lineage Chitralada). Therefore, there were fortnightly visits, being possible to collect water and submits them to physical and chemical studies through the Kit Acqua Supre, Oximeter end disc de secchi, being these variables: temperature, transparency, alkalinity, hardness, dissolved oxygen (OD), total ammonia, nitrite, carbon dioxide, and hydrogen potential (pH). The measured data were submited to descriptive statistics, allowing you to see the average of the corresponding values. Results related to the hydrological parameters such as OD in the water reached values between $6,92 \mathrm{a} 9,63 \mathrm{mg} / \mathrm{L}$; carbon dioxide dissolved in water with an average of $17,02 \mathrm{mg} / \mathrm{L}$; nitrite, meet the average $0,2 \mathrm{mg} / \mathrm{L}$ and total ammonia, with averaging $2,09 \mathrm{mg} / \mathrm{L}$. This study has economic importance in exploring the tilapicultura alternatively, opening possibility for sustainability and agribusiness.
\end{abstract}

Keywords: digged tank, hydrological parameters, pisciculture

\section{INTRODUÇÃO}

O Brasil vem se destacando como uma eminente potência na expansão da atividade aquícola, especificamente a piscicultura, isso se dá graças à abundância dos recursos hídricos e o clima, que favorece o desenvolvimento dos peixes, em especial a tilápia (Oreochromis niloticus) (DANTAS, 2013). Segundo dados do Ministério da Pesca e aquicultura - MPA (2012), a produção aquícola nacional teve um aumento de $31,2 \%$ no período correspondente ao triênio 2008 - 2010, sendo que, a piscicultura representou em 2010, $82,3 \%$ da produção total brasileira.

O Nordeste brasileiro tem o segundo lugar na produção aquícola continental, onde se destaca os estados do Ceará e Bahia com 38.090,9 e 16.256,6 toneladas ( $t$ ), dados divulgados em 2010 revelam que de um total de 78.578,5 t para a região nordeste, a Paraíba alcançou uma produção anual de 1.292, 57 $\mathrm{t}$, índice considerado relativamente baixo comparado com outros estados, de acordo com o (MPA, 2012). Porém, segundo dados do IBGE (2014) a produção de peixes para o Estado do Rio Grande do Norte, na qual faz divisa com a Paraíba, alcançou um valor de 2.390,233 t, sendo um dos grandes impulsionadores o Estado de Rondônia, com uma produção despescada nesse mesmo ano em torno de 75, 02 mil toneladas de peixes. O estudo entre os dois estados é de suma importância, haja vista que parte da

Recebido em 29/06/2018; Aceito para publicação em 27/09/2018

${ }^{1}$ Universidade Federal da Paraíba

${ }^{2}$ Universidade Federal de Campina Grande

*E-mail: djairdamata@gmail.com 
produção de pescado e consumo se relacionam entre as mesmas, devido ao fluxo de comercio.

É fato que a piscicultura tem sua dada importância e lugar de destaque. Dias - Neto (2010) ressalta que o pescado, é uma real possibilidade na implementação da balança comercial brasileira, porém, essa realidade só é possível com investimentos massivos em pesquisa e tecnologias que respeitem as condições do animal e do meio ambiente. $\mathrm{O}$ mesmo autor também alerta que a pesca extrativa se encontra em declínio, fato correspondente a pesca desordenada na década de 80, e segundo a Food and Agriculture Organization of the United Nations - FAO (2009), 80\% da pesca extrativa encontram-se em exploração máxima. As reservas naturais de pescado não conseguem mais suprir as necessidades do consumidor. Nesse contexto, o uso de tanques escavados vem se destacando como uma atividade de retorno econômico.

O cultivo de tilápias é uma das grandes atividades em potencial, já que a espécie apresenta uma boa adaptabilidade e resistência. A tilápia do Nilo (O. niloticus) é considerada a principal espécie de peixe cultivada no Brasil (BARROSO et al., 2015). Sampaio (2010) relata que a produção de pescado nacional gira em torno de 1 milhão de toneladas e segundo Oliveira e Santos (2015) a produção aquícola em 2030 deverá corresponder a $50 \%$ de pescado em todo o mundo.

A piscicultura é uma atividade em pleno desenvolvimento, mas, ainda está passando por uma série de processos e inclusões de novas tecnologias, porém, devido ao seu custo de investimento e retorno econômico rápido, a atividade vem se mostrando como uma alternativa sustentável na implementação econômica dos pequenos produtores (ARAUJO; MORAES, 2010).

A escassez de água é um dos principais problemas enfrentados pela atividade piscícola. Nesse contexto o uso eficiente dos recursos hídricos tem permitido o avanço da atividade, pois além do uso para os tanques, a mesma água pode ser empregada para outros fins, a exemplo da agricultura, do cultivo de hortaliças e pastagens (OLIVEIRA; SANTOS, 2015).

Verifica-se que as variáveis físicas e químicas da água regem $o$ ganho de peso (biomassa), crescimento e produtividade de tilápias cultivadas em tanques escavados, o que assegura uma boa produção, refletindo em ganhos sociais, geração e distribuição de renda, incentivo ao associativismo e preservação ambiental se comparado com a pecuária bovina e caprina. Dados pertinentes a esse sistema de cultivo, ainda se encontram escassos e pouco difundidos na comunidade cientifica (VIDAL, 2016).
A tilápia do Nilo (O. niloticus) foi introduzida no nordeste brasileiro em 1971 pelo Departamento Nacional de Obras Contra a Seca (DNOCS), visando o peixamento dos reservatórios públicos da região (OLIVEIRA et al., 2007). Nesse sentido é possível constatar que a espécie tem um historio intimo como alternativa de alimento para combater a fome.

A tilápia ( $O$. niloticus) é atualmente o principal cultivo do sistema aquícola brasileiro, sendo a espécie mais utilizada na piscicultura. Pois ela se adapta bem as condições de clima quente, seja em tanques escavados, gaiolas ou tanques-rede. Uma de suas características é a adaptação ao consorcio com outras espécies, a exemplo o camarão (Macrobrachium rosenbergii), otimizando e ampliando o sistema de produção (BARROSO et al., 2015; MATA et al., 2016).

Na região Nordeste do Brasil o cultivo de tilápia em tanques escavados é considerada uma atividade em pleno desenvolvimento. Fitzsimmons (2015) consolida com a confirmação de que a mesma é cultivada em todos os continentes do mundo, especialmente em regiões de clima tropical, sendo catalogadas pela FAO (2009) em mais de 140 países produtores. A espécie $O$. niloticus segundo Popma e Masser (1999) na década de 90 a tilápia mais produzida em todo o mundo. Já dados do IBGE (2014) revelam que a espécie se encontra presente em 1.878 municípios brasileiros. Nos últimos 5 anos o cultivo teve um crescimento anual considerável entre 20 - 25\%. Em 2014 a atividade movimentou 1 bilhão de Reais (R\$) com uma produção de 198,49 mil toneladas despescada, o equivalente a $41,9 \%$ do total da piscicultura nacional (IBGE, 2014).

O sistema de cultivo em tanques escavados pode integrar outras atividades agropecuárias, que pode vir a trazer benefícios ao produtor rural, em razão de um melhor aproveitamento de seus recursos como a água, energia e mão de obra. Essa água bem manejada poderá ser destinada a irrigação de pastagens, pomares, hortaliças, etc. (SEBRAE, 2014).

Além de promover e desenvolver a sustentabilidade das famílias agricultoras, o pescado vem se destacando como uma fonte nutricional de valor proteico nobre e de baixo custo, o que permite uma melhor acessibilidade pelo consumidor. Savitiski (2013) relata que a crescente demanda pela carne de pescado é influenciada pelos seus benefícios nutricionais como o valor de gordura presente na carne que varia entre 0,5 a $15 \%$. Boccaleto e Mendes (2009) também enfatizam que a gordura encontrada em peixes é rica em ômega 3, que dentre os seus benefícios está a prevenção contra doenças cardiovasculares. Porém, de acordo com Koche (2013), apesar do notável crescimento da aquicultura, em especial a piscicultura, o 
consumo de carne de peixe pela população brasileira é em média $9 \mathrm{Kg}$ (Quilogramas) por habitante ao ano, sendo considerado o abaixo do mínimo recomendado pela Organização Mundial da Saúde (OMS) que estipula uma média de $12 \mathrm{Kg}$ por habitante ao ano.

A qualidade da água é observada de acordo com as variáveis físicas, químicas e biológicas através do monitoramento, práticas indispensáveis na piscicultura, tendo em vista que características como oxigênio dissolvido, gás carbônico, temperatura, $\mathrm{pH}$, alcalinidade, dureza, amônia, nitrito e transparência da água interferem nos processos fisiológicos do animal, refletindo no ganho da biomassa final (OLIVEIRA et al., 2010; LIMA et al. 2013). Guimalhães (2012) reforça que para um bom cultivo a água deve existir em qualidade e quantidade, sempre que possível deve-se conhecer a sua procedência, bem como, as redondezas de sua propriedade, observando se existem águas poluídas por defensivos agrícolas, resíduos industriais e esgotos que possam contaminar o plantel de cultivo.

Produzir com eficiência exige-se bom planejamento, porém, dentre os principais desafios apontados por Sidonio et al. (2012) o crescimento e desenvolvimento do setor encontra-se em termos burocráticos relacionados a regularização da atividade, incluindo os processos de licenciamento ambiental e recursos hídricos, além dos desafios na regulamentação para o comercio do produto. Diante dos desafios enfrentados pela piscicultura Oliveira e Santos (2015) chamam atenção para a escassez de água, fator este, limitante para todas as atividades agropecuárias.

Inúmeras são as variáveis e processos que influenciam a qualidade da água (OLIVEIRA, 2009). Segundo Lima et al. (2013), o monitoramento da temperatura, transparência, oxigênio dissolvido, pH, alcalinidade, salinidade, gás carbônico, dureza, nitrito e amônia são fatores intimamente ligados a qualidade do cultivo. Segundo Apolinário et al. (2015), irregularidades na água do cultivo podem afetar a produção da tilápia e, até mesmo a sua qualidade. Portanto, o piscicultor sempre deve estar a observar o viveiro, verificando aspectos ou variáveis que possam interferir na produtividade, evitando assim, futuros transtornos. Mata (2013) ressalta que viver no semiárido brasileiro é conviver com as constantes estiagens e adversidades impostas pelo meio, mas estas não impedem o desenvolvimento de técnicas, projetos e programas que visem à sustentabilidade e uma base duradoura, ampliando as condições de vida das famílias habitantes dessa região.

Nesse âmbito, objetivou-se analisar os parâmetros físicos e químicos da água e o desempenho produtivo da tilápia ( $O$. niloticus) em tanques escavados na propriedade rural Sítio Gurjaú no município de Coronel Ezequiel - RN, bem como: Realizar o controle do crescimento heterogêneo nos cultivos em tanques escavados, através da adoção de práticas de manejo adequadas durante as biometrias e a alimentação dos peixes cultivados; Avaliar o cultivo de tilápias em tanques escavados como uma potencial alternativa no que diz respeito a sistema de cultivo, observando os reflexos positivos socioeconômicos e socioeducativos e dar suporte a atividade, proporcionando o desenvolvimento do pescado, respeitando o meio ambiente.

\section{MATERIAL E MÉTODOS}

O presente estudo foi realizado na propriedade rural Sítio Gurjaú, localizado no município de Coronel Ezequiel - Rio Grande do Norte/RN a 14 $\mathrm{km}$ da Universidade Federal de Campina Grande, Campus Cuité - PB/Centro de Educação e Saúde CES. A pesquisa decorreu entre Julho/2016 a julho/2017, sendo possível a constatação de dois ciclos de cultivo, o primeiro correspondendo de abril a setembro de 2016, pois ao iniciar a pesquisa os tanques escavados já se encontravam povoados e o $2^{\circ}$ ciclo de cultivo de outubro/2016 a abril/2017.

Os dados obtidos foram submetidos à estatística descritiva simples permitindo a interpretação da média dos resultados, sendo estes comparados com os parâmetros de qualidade fornecidos pelo manual da empresa ALFAKIT, assim como comparações com demais autores da área piscícola (Tabela 1). 
Tabela 1. Recomendações para os parâmetros físicos e químicos da água de cultivo para tilápia e seus respectivos valores.

\begin{tabular}{lccc}
\hline \multicolumn{1}{c}{ PARÂMETRO } & UNIDADE & VALORES RECOMENDADOS & RECOMENDAÇÕES \\
\hline Temperatura & ${ }^{\circ} \mathrm{C}$ & 20 até 29 & Oliveira (2000) \\
Transparência & $\mathrm{Cm}$ & Abaixo de 60 e acima de 10 & Oliveira (2000) \\
Oxigênio Dissolvidos $(\mathrm{OD})$ & $\mathrm{mg} / \mathrm{L}$ & 4 até 8 & Kubitza (2017) \\
Potencial Hidrogeniônico $(\mathrm{pH})$ & $\mathrm{pH}$ & 4,5 a 10,5 & Garcia, Santos e Garcia (2009) \\
Alcalinidade & $\mathrm{mg} / \mathrm{L}$ & 20 até 300 & Kubitza (2009) \\
Amônia Total & $\mathrm{mg} / \mathrm{L}$ & $<4$ & Kubitza (2017) \\
Dureza & $\mathrm{mg} / \mathrm{L}$ & $>20$ & Cavalcante et al. $(2012)$ \\
Nitrito & $\mathrm{mg} / \mathrm{L}$ & Até 0,5 & Rossi (2014) \\
Gás Carbônico $\left(\mathrm{CO}^{2}\right)$ & $\mathrm{mg} / \mathrm{L}$ & 5 a 25 & Kubitza (2003) \\
\hline
\end{tabular}

Legenda: Recomendações com base nos trabalhos e autores de: "Single orpaired increase of total alkalinity and hardness of water for cultivation of Nile tilapia juveniles, Oreochromis niloticus" Cavalcante et al. (2012).; "Análise dos parâmetros físico-químicos dos viveiros de camarão na grande Aracaju - Sergipe" Garcia, Santos e Garcia (2009).; "Piscicultura em Rondônia: a força de um setor organizado" Kubitza (2017).; "Produção de tilápias em tanques de terra: estratégias avançadas no manejo" Kubitza (2009).; "Qualidade da água: no cultivo de peixes e camarões" Kubitza (2003).; "Manual de qualidade da água para aquicultura" Oliveira (2000).; "A utilização da tecnologia de bioflocos (TBF) na piscicultura: histórico e principais técnicas de manejo de sistema" Rossi (2003).

O local conta com quatro tanques escavados para a produção de tilápias com dimensões (Tanque 1 Comprimento $(56 \mathrm{~m}) \times$ largura $(18 \mathrm{~m}) \times$ profundidade $(1,60 \mathrm{~m})$; Tanque 2 - Comprimento $(16 \mathrm{~m}) \mathrm{x}$ largura $(15 \mathrm{~m}) \times$ profundidade $(1,60 \mathrm{~m})$; Tanque 3 Comprimento $(40 \mathrm{~m}) \mathrm{x}$ largura $(15 \mathrm{~m}) \mathrm{x}$ profundidade $(1,80 \mathrm{~m})$; Tanque 4 - Comprimento $(35 \mathrm{~m}) \mathrm{x}$ largura $(12 \mathrm{~m}) \mathrm{x}$ profundidade $(1,60 \mathrm{~m})$, além de um reservatório natural que rende a cada 3 dias 400.000 $\mathrm{L}$ de água. Nas visitas e acompanhamento da atividade piscícola, foram coletas amostras de água no horário de 8:00 às 14:00 horas para análises físicas e químicas, sendo possível determinar a sua qualidade para a piscicultura.

Nesse contexto, foi de fundamental importância acompanhar as etapas de povoamento dos alevinos por tanque, que nesse caso, segundo o proprietário, trabalhou-se com "alevinões", que nada mais são do animais com um tempo maior de desenvolvimento, alevinos juvenis, de aproximadamente $12 \mathrm{~cm}$, com um peso em torno de $30 \mathrm{~g}$; Monitoramento sistemático dos parâmetros físicos e químicos da água disponível para o cultivo, com coleta de água quinzenal; Confecção de relatórios, após cada visita e Monitoramento dos parâmetros hidrológicos como: temperatura, transparência, alcalinidade total, dureza, $\mathrm{pH}$, oxigênio, amônia total, nitrito e, gás carbônico.

Uma das medidas adotadas na pesquisa foi o acompanhamento da alevinagem e despesca que se deu por meio da tarrafa, verificando o peso dos animais, obtendo-se a média de peso ganho, que segundo o proprietário, o consumidor prefere uma média de $700 \mathrm{~g}$ por animal.

Para analisar a qualidade da água contou-se como auxilio do kit de análises da empresa Acqua Supre, por meio de titulação, bem como os equipamentos: oxímetro, balança digital e disco de secchi.
É evidente que a boa qualidade da água reflete em uma produtividade considerável, sendo assim, o patamar adotado, como teto nessa pesquisa foi de 1,5:1, ou seja, para cada Kg (Quilograma) de peixe despescado, é necessário no máximo $1,5 \mathrm{Kg}$ de rações para sua produção.

Ao final da pesquisa, os respectivos dados foram interpretados e calculados pelas fórmulas 1 e 2, o que permitiu identificar a evolução da atividade na propriedade rural.

(1ํ Fórmula)

$$
\begin{aligned}
& \text { PEPVPT } / \text { Kg } \\
& =\frac{\text { № de Peixes por tanque x Média de Peso Final }}{100}
\end{aligned}
$$

Em que: PEPVPT: Produção Estimada de Peixe Vivo Por Tanque

\section{(2 ${ }^{\text {a }}$ Fórmula)}

$$
\begin{aligned}
& \text { GRAPT } / \text { Kg } \\
& =\frac{\text { № de Peixes por tanque x Ração Consumida }}{\text { № de Peixe Total }}
\end{aligned}
$$

Em que: GRAPT: Gasto de Ração Por Tanque.

O consumo de ração do animal em um período de tempo $\mathrm{x}$ ganho de peso (Biomassa) é entendida como conversão alimentar (CA), que segundo Faria et al. (2013) e Sebrae (2014), para tilápia a proporção de CA deve ser menor que 1,5:1 ou seja, para cada $\mathrm{kg}$ produzido é necessário $1,5 \mathrm{~kg}$ de ração a partir dos dados correspondentes é feito o cálculo para CA, sendo suas formulas adaptadas a partir do manual do piscicultor (Fórmulas 3, 4 e 5), de autoria Sebrae (2008). 
(3a Fórmula)

Peso Inicial $(\mathrm{Kg})=\frac{\text { № de Peixes Total x Peso Inicial }}{1000}$

(4áFórmula)

Biomassa $=$ Produção Estimada de Peixe Vivo Peso Inicial

(5aㅡ Fórmula)

Conversão Alimentar $(\mathrm{CA})=\frac{\text { Ração Gasta }}{\text { Biomassa }}$
A criação em tanques escavados é uma alternativa em contrapartida à pesca extrativa, que ao longo dos anos acarretou diversos impactos ambientais, promovendo o desequilíbrio entre as espécies.

\section{RESULTADOS E DISCUSSÃO}

Todo e qualquer dado obtido é de total importância para uma pesquisa, pois revela se ocorreram alterações nas variáveis analisadas.

Tabela 2: Parâmetros hidrológicos, físicos e químicos, aferidos no período de julho de 2016 a abril de 2017.

\begin{tabular}{|c|c|c|c|c|c|c|c|c|c|c|c|c|c|c|}
\hline \multirow[b]{2}{*}{ Parâmetros } & \multicolumn{10}{|c|}{ Meses } & \multirow[b]{2}{*}{ Uni. } & \multirow[b]{2}{*}{ Méd. } & \multirow[b]{2}{*}{ Máx. } & \multirow[b]{2}{*}{ Mín. } \\
\hline & $\begin{array}{l}\text { Jul. } \\
2016\end{array}$ & $\begin{array}{l}\text { Ago. } \\
2016\end{array}$ & $\begin{array}{l}\text { Set. } \\
2016\end{array}$ & $\begin{array}{l}\text { Out. } \\
2016\end{array}$ & $\begin{array}{l}\text { Nov. } \\
2016\end{array}$ & $\begin{array}{l}\text { Dez. } \\
2016\end{array}$ & $\begin{array}{l}\text { Jan. } \\
2017\end{array}$ & $\begin{array}{l}\text { Fev. } \\
2017\end{array}$ & $\begin{array}{l}\text { Mar. } \\
2017\end{array}$ & $\begin{array}{l}\text { Abr. } \\
2017\end{array}$ & & & & \\
\hline Temp. & 23,67 & 23,3 & 26,5 & $*$ & 24,56 & 24,95 & $*$ & 22,9 & 21,42 & 22,9 & ${ }^{\circ} \mathrm{C}$ & 23,3 & 26,5 & 21,42 \\
\hline Trans. & 16 & 19 & 23,5 & $*$ & 20 & 10 & $*$ & 20,5 & 10,75 & 10 & $\mathrm{Cm}$ & 16,21 & 23,5 & 10 \\
\hline Alca. & $*$ & 12 & 9,75 & 24 & 20,25 & 31,5 & 21,75 & 19 & 18,75 & 16,5 & $\mathrm{mg} / \mathrm{L}$ & 19,27 & 31,5 & 9,75 \\
\hline Dur. & $*$ & 22,5 & 19,5 & 20 & 18,75 & 24 & 23,25 & 28,5 & 27,75 & 15 & $\mathrm{mg} / \mathrm{L}$ & 22,13 & 27,75 & 15 \\
\hline $\mathrm{pH}$ & 5,71 & 5,5 & 5,64 & 5,6 & 5,6 & 5,5 & 5,75 & 5,5 & 5 & 5,5 & $\mathrm{pH}$ & 5,5 & 5,75 & 5 \\
\hline OD & $*$ & $*$ & 6,92 & $*$ & 8,78 & 9,63 & * & 8,25 & 8,48 & 9,13 & $\mathrm{mg} / \mathrm{L}$ & 8,63 & 9,63 & 6,92 \\
\hline Nitrito & * & 0,1 & 0,1 & 0,2 & 0,3 & 0,2 & 0,2 & 0,25 & 0,25 & 0,1 & $\mathrm{mg} / \mathrm{L}$ & 0,2 & 0,3 & 0,1 \\
\hline Amônia Total & 1,71 & 3,15 & 2,05 & 2,24 & 1,56 & 2,4 & 0,9 & 1,5 & 2,8 & 2,4 & $\mathrm{mg} / \mathrm{L}$ & 2,07 & 3,15 & 0,9 \\
\hline $\mathrm{CO}^{2}$ & $*$ & 20 & 16 & 10,75 & 20 & 13 & 15 & 22,5 & 24 & 12 & $\mathrm{mg} / \mathrm{L}$ & 17,02 & 24 & 12 \\
\hline
\end{tabular}

Legenda: Em que: OD (Oxigênio Disponível); pH (Potencial Hidrogeniônico); $\mathrm{CO}^{2}$ (Gás Carbônico); ${ }^{\circ} \mathrm{C}$ (Graus Celsius); $\mathrm{Cm}$ (Centímetro); mg/L (Miligramas por Litro); * (propriedade não aferida em decorrência de falhas de equipamentos); (') Abreviação.

A temperatura apresenta grande influência na quantidade de $\mathrm{O}^{2}$ dissolvido na água. Quanto mais quente a água menos oxigênio ela apresenta, já que a temperatura influencia na proliferação de microrganismos e no processo osmótico do animal, além disso, atividades fisiológicas como a respiração, digestão, excreção, alimentação e movimentos contribuem para o maior consumo de oxigênio. Sendo assim, os dados obtidos no decorrer da pesquisa, revelam resultados com uma média para temperatura em torno de $23,3{ }^{\circ} \mathrm{C}$, considerado promissor no que diz respeito qualidade da água (Tabela 2).

A temperatura teve uma média de $23,3{ }^{\circ} \mathrm{C}$, com máxima em torno de 26,5 e mínima de $21,42{ }^{\circ} \mathrm{C}$, permanecendo dentro do aceitável para o desenvolvimento dos peixes, no entanto, análises referentes aos meses de outubro/2016 e janeiro de 2017, não foram possíveis, pois em uma pesquisa dessa magnitude falhas em equipamentos não estão isentos.

A transparência é a capacidade de penetração da luz na água. O parâmetro físico de transparência pode indicar a quantidade de plâncton presente na água, quanto menor a turbidez, maior a matéria orgânica e nutriente, bem como, uma menor oferta de oxigênio disponível.
Neste trabalho, a transparência teve uma máxima de $23,5 \mathrm{~cm}$ de profundidade (Tabela 2), mas, não implica em irregularidades de outros parâmetros.

De modo geral, a média de alcalinidade alcançada durante o acompanhamento desse parâmetro hidrológico foi de 19,27 mg/L (Tabela 1).

Apesar dos resultados abaixo do estipulado, os mesmos encontram-se dentro da faixa regular no que diz respeito as condições pertinentes a produtividade da tilápia do Nilo, com máxima em 31,5 mg/L.

No decorrer do acompanhamento dos parâmetros químicos dos meses de outubro/2016, novembro/2016, dezembro/2016 e janeiro/2017, a alcalinidade teve uma média de $24,37 \mathrm{mg} / \mathrm{L}$ acarretando em um bom poder tampão da água. Porém, os meses de agosto/2016, setembro/2016, fevereiro/2017, março/2017 e abril/2017, apresentam valores inferiores ao estipulado, com valores em média de 15,2 mg/L e mínima de 9,75 $\mathrm{mg} / \mathrm{L}$, o que implica em um poder tampão reduzido, bem como numa maior flutuação dos valores de $\mathrm{pH}$, em decorrência dos processos fotossintéticos e respiratórios nos viveiros.

O cultivo da tilápia em tanques escavados proporciona benefícios como poder tampão sobre o $\mathrm{pH}$, influência na atividade primária (fotossíntese), 
manutenção e produção de fitoplâncton que faz parte da alimentação dos peixes.

No cultivo de tilápia $O$. niloticus à água deve existir em quantidade e qualidade.

Nesse contexto, no decorrer do acompanhamento dos meses de setembro/2016, novembro/2016 e abril/2017 foram alcançadas uma média de $17,75 \mathrm{mg}$ de $\mathrm{CaCo}_{3} / \mathrm{L}$ (Tabela 2), implicando na má formação do fitoplâncton.

A dureza alcançada nos meses de agosto/2016, outubro/2016, dezembro/2016 e de janeiro a março/2017 alcançaram uma média de $24,33 \mathrm{mg} / \mathrm{L}$ de $\mathrm{CaCo}_{3}$ (Tabela 2), que implica na tendência de um melhor poder tampão. De modo geral, a média do acompanhamento é de $22,13 \mathrm{mg} / \mathrm{L}$.

De uma forma geral foi possível observar que o cultivo da tilápia (O. niloticus) em tanques cavados manteve uma média de $5,5 \mathrm{mg} / \mathrm{L}$ (Tabela 2), por sua vez, os parâmetros encontram-se dentro dos requisitos recomendados para a produção piscícola.

Valores abaixo de 4,5 e acima de $10,5 \mathrm{mg} / \mathrm{L}$ causam mortalidade significativa no cultivo. Os valores alcançados nessa pesquisa durante os meses de julho/2016 a dezembro/2016 e janeiro/2017 a abril/2017 se mantêm numa média de $\mathrm{pH}$ 5,5 o que implica em valores com tendência a acidez, mas aceitáveis.

A concentração de oxigênio na água depende de inúmeros fatores. Por exemplo, a temperatura: quanto mais fria a água, mais oxigênio pode ser dissolvido; salinidade: quanto mais sais na água, menos oxigênio; fotossíntese e respiração: dependendo da concentração dos microrganismos (microalgas ou fitoplâncton) as concentrações de oxigênio se elevam durante o dia em decorrência da fotossíntese e caem durante a noite em virtude da respiração.

De acordo com os dados obtidos, os meses de setembro/2016, novembro/2016, dezembro/2016, fevereiro/2017, março/2017 e abril/2017 mostram um patamar de qualidade, apresentando resultados entre 6,92 a 9,63 mg/L (Tabela 2).

O oxigênio dissolvido é provavelmente a variável de qualidade mais importante para o cultivo de peixes, uma vez que a falta desse recurso limita ou encerra a atividade, ocasionando perdas econômicas.

A amônia é o principal resido nitrogenado proveniente do catabolismo de proteínas. $\mathrm{O}$ nitrogênio amoniacal é proveniente da decomposição da matéria orgânica, de restos de ração e excrementos, onde em sua grande quantidade dissolvida na água e, em grandes concentrações é letal para os peixes.

No decorrer da pesquisa a concentração de amônia total alcançou uma média de $2,07 \mathrm{mg} / \mathrm{L}$ de $\mathrm{NH}_{3}$ (Tabela 2), sendo considerado um ótimo valor para cultivo de tilápia em tanque escavado
A exposição contínua das tilápias à concentrações irregulares de amônia pode resultar em uma morte significativa dos animais ou condicionar propensões a doenças. Tornando-se necessário o cuidado na oferta de ração e renovação da água sempre que necessário, pois as excretas e a decomposição da matéria orgânica têm forte impacto na qualidade da água.

O monitoramento diário desse parâmetro é uma forma de prevenir futuros transtornos, sendo está considerada uma ferramenta que o piscicultor dispõe para controlar os níveis de amônia dentro dos limites adequados.

Durante todo o período de cultivo os resultados obtidos nas análises mostram que o Nitrito presente na água dos viveiros escavados está dentro dos padrões de qualidade para uma boa criação, pois nenhum resultado, ultrapassou $0,3 \mathrm{mg} / \mathrm{L}$ de $\mathrm{NO}_{2}$ (Tabela 2).

De acordo com o Kit de análises da Acqua Supre os valores de $\mathrm{NO}_{2}$ não devem ultrapassar $1 \mathrm{mg} / \mathrm{L}$. De um modo geral, a média alcançada nessa pesquisa para o nitrito é de $0,2 \mathrm{mg} / \mathrm{L}$ de $\mathrm{NO}_{2}$.

Os compostos nitrogenados têm sua dada parcela negativa na produção da tilápia, mas também tem sua importância no ciclo produtivo e sobrevivência do animal, pois as bactérias presentes na água depuram as concentrações nitrogenadas utilizado esses compostos na síntese proteica.

$\mathrm{O}$ gás carbônico $\left(\mathrm{CO}^{2}\right)$ na piscicultura é decorrente das fontes de respiração das algas, das macrófitas, dos peixes, do zooplancton e dos processos microbiológicos de decomposição orgânica, as altas concentrações de gás carbônico, superior a $30 \mathrm{mg} / \mathrm{L}$ podem afetar o desempenho dos peixes, porém a espécie de $O$. niloticus é muito resistente, conseguindo sobreviver e se adequar a essa ocasionalidade.

Os resultados para $\mathrm{CO}^{2}$ dissolvido na água durante a pesquisa alcançou uma média de 17,02 $\mathrm{mg} / \mathrm{L}$ (Tabela 2).

A pesar do forte impacto do $\mathrm{CO}^{2}$ no desempenho e sobrevivência dos peixes, o mesmo tem um papel fundamental no ciclo produtivo desses animais. Os processos fotossintéticos estão diretamente relacionados ao crescimento da biomassa planctônica, na qual o mesmo juntamente com outros processos biológicos acrescenta ou remove o gás carbônico da água. Vale salientar que diversos microrganismos relacionados esses processos são fonte alimentícias da tilápia.

Os níveis de gás carbônico devem ser monitorados periodicamente, mantendo o equilíbrio desse parâmetro. $\mathrm{O}$ produtor deve sempre ter um olhar atento na renovação da água e na quantidade de ração ofertada para os animais. 
Os dados obtidos no decorrer da pesquisa, revelam resultados com uma média para temperatura em torno de $23,3{ }^{\circ} \mathrm{C}$, considerado promissor no que diz respeito a qualidade da água. Resultados similares foram encontrados por Dantas, Silva e Apolinário (2015), respectivamente com uma média de $24,5{ }^{\circ} \mathrm{C}$ para tilápia cultivada em tanques-rede durante o período seco de agosto/2011 a janeiro/2012; Rosa, Noleto e Ribeiro (2014) com uma média de $24,5^{\circ} \mathrm{C}$; Landell (2007) com resultados de $18,9{ }^{\circ} \mathrm{C}$ no inverno a $27,4{ }^{\circ} \mathrm{C}$ no verão para tilápias em tanques-rede, e Castellani et at. (2011) apontou resultados anuais variando de 16 a $28{ }^{\circ} \mathrm{C}$ no policultivo de tilápias.

O Manual de qualidade da água para aquicultura de Oliveira (2000) recomenda valores de 20 a $29^{\circ} \mathrm{C}$ para tilápia. Dantas e Apolinário (2014) concordam que essa faixa permite o bom desenvolvimento produtivo do animal. Fernandes (2014) enfatiza que para os casos de temperatura abaixo de $20{ }^{\circ} \mathrm{C}$, o piscicultor deve realizar o mínimo de manejo possível, pois tal parâmetro tem forte influência nos processos fotossintéticos e consequentemente disponibilidade de oxigênio dissolvido na água.

A transparência média foi de $16,21 \mathrm{~cm}$ de profundidade (Tabela 2). Comarella (2014) complementa que sedimentos em excesso podem causar coloração verde escura na água, o que impede uma boa análise de transparência, mas, não implica em irregularidades de outros parâmetros. Resultados semelhantes foram alcançados por Duarte et al. (2014), com valores de 15 a $40 \mathrm{~cm}$ de profundidade. Com base no "Manual de qualidade da água para a aquicultura" de Oliveira (2000), a média dos valores respectivamente $16,21 \mathrm{~cm}$ encontra-se dentro dos padrões de qualidade da água, pois em viveiros de tilápias é admissível valor menor que $20 \mathrm{~cm}$, sendo este considerado até $10 \mathrm{~cm}$, pois valores inferiores ocasionam estresse em relação ao oxigênio, levando a morte dos peixes.

De acordo com Leira et al. (2017), a faixa ideal para a piscicultura é em torno de 20 a $40 \mathrm{~cm}$ de profundidade. Porém essa estimativa é relativa, o autor ainda argumenta que a turgidez da água pode ser comprometida pela ação dos nutrientes Ferro $(\mathrm{Fe})$ e Manganês (Mn).

De modo geral, a média de alcalinidade alcançada durante o acompanhamento desse parâmetro hidrológico foi de 19,27 mg/L (Tabela 1). Ferraz e Amaral (2010) relatam valores similares entre 14 a $26 \mathrm{mg} / \mathrm{L}$ no seu trabalho de análise de variação nictemeral dos parâmetros físico-químicos da água de em viveiro de cultivo de tilápia. O trabalho de Saraiva el al. (2009) "Densidades de estocagem de juvenis da tilápia Oreochromis niloticus (linhagem Chitralada) cultivados em tanques-rede", relata valores menores que $20 \mathrm{mg} / \mathrm{L}$,
Silva (2014) encontra-se com resultados semelhantes aos obtidos no decorrer da pesquisa, com valores de alcalinidade de $(14,6$ - 28,5) mg/L. Apesar dos resultados abaixo do estipulado, os mesmos encontram-se dentro da faixa regular no que diz respeito as condições pertinentes a produtividade da tilápia do Nilo.

A alcalinidade em tanques escavados tem intima relação nos benefícios como poder tampão sobre o $\mathrm{pH}$, influência na atividade primária (fotossíntese), manutenção e produção de fitoplâncton que faz parte da alimentação dos peixes, também tem reflexo direto na cor da água, dessa forma é importante sempre manter os níveis acima de $30 \mathrm{mg} / \mathrm{L}$, devendo ser acompanhados diariamente (KUBTZA, 2009).

A dureza alcançada nos meses de agosto/2016, outubro/2016, dezembro/2016 e de janeiro a março/2017 alcançaram uma média de $24,33 \mathrm{mg} / \mathrm{L}$ de $\mathrm{CaCo}_{3}$ (Tabela 2), que implica na tendência de um melhor poder tampão. De modo geral, a média do acompanhamento é de $22,13 \mathrm{mg} / \mathrm{L}$. Leite (2009) e Silva (2014) em seus trabalhos relatam valores de 25,38-22,4 $\mathrm{mg} / \mathrm{L}$ similares aos alcançados na presente pesquisa, os autores Lima et al. (2008) e Carmo et al. (2008) também expressam resultados correspondentes a 26 e 15,61-47,84 mg/L, valores próximos aos resultados obtidos.

De acordo com Oliveira (2000), Wambach (2012) e Ushizima (2016), os valores de dureza devem ser superiores a $20 \mathrm{mg} / \mathrm{L} \mathrm{CaCo}_{3}$ (carbonato de cálcio), pois representa um bom poder tampão da água, na qual tem influência direta na produtividade dos peixes. Valores inferiores devem ser considerados.

Pode-se concluir que os resultados de dureza alcançados no decorrer da pesquisa são encontrados com valores similares em outros trabalhos, Graef et al. (2007) acrescenta que são poucos os estudos existentes sobre a influência da dureza no desenvolvimento dos peixes.

Segundo Garcia, Santos e Garcia (2009), valores abaixo de 4,5 e acima de $10,5 \mathrm{mg} / \mathrm{L}$ causam mortalidade significativa no cultivo. Durante os meses de julho/2016 a dezembro/2016 e janeiro/2017 a abril/2017 se mantêm numa média de 5,5 (Tabela 2), o que implica em valores com tendência a acidez, mas aceitáveis, o que não os torna isentos de proporcionar estresse ao animal (ABRUNHOSA, 2011). O autor ainda enfatiza que valores do Potencial Hidrogeniônico entre 5 a 6 $\mathrm{mg} / \mathrm{L}$ são toleráveis, porém causa retardamento no crescimento dos peixes, maior tempo de tanque e alimentação, refletindo em prejuízos.

A produção de peixes em tanques escavados, com $\mathrm{pH}$ na faixa de $4,6 \mathrm{mg} / \mathrm{L}$ acomete na diminuição do crescimento do peixe (NETO et al., 2016). De acordo com Kubitza (2009) a produção da 
tilápia em água doce, com variações da água entre $(5,5$ a 7,0$)$ com persistência no patamar de acidez causa prejuízos no crescimento, na conversão alimentar e na resposta a doenças, apresentando uma imunológica baixa para doenças. De acordo com o (SEBRAE, 2014) resultados dos valores do $\mathrm{pH}$ abaixo de 4,5 e acima de $10,5 \mathrm{mg} / \mathrm{L}$ causam a morte dos animais.

As concentrações de oxigênio dissolvido na água devem ser mantidas, preferencialmente em quantidades superiores a $4,5 \mathrm{mg} / \mathrm{L}$ (KUBITZA, 2017). Quando a concentração de oxigênio é adequada, os peixes podem tolerar concentrações de gás carbônico em níveis a cima de 10mg/L (MERCANTE; SILVA; COSTA, 2006). HenrySilva e Camargo (2008) complementam que os teores de oxigênio dissolvido na água podem sofrer grande baixa em decorrência do aumento da biomassa dos peixes, bem como ao arraçoamento e aos metabólitos dos peixes.

De acordo com os dados obtidos, os meses de setembro/2016, novembro/2016, dezembro/2016, fevereiro/2017, março/2017 e abril/2017 mostram um patamar de qualidade, apresentando resultados entre 6,92 a 9,63 mg/L (Tabela 2).

Resultados similares de oxigênio dissolvido na água foram constatados por Barbosa et al. (2009) em torno de 6,31 mg/L; Mercante, Silva e Costa (2006) com valores entre 5,20 a $12,40 \mathrm{mg} / \mathrm{L}$ e, Ferraz e Amaral (2010) com valores em torno de 6,9 a 9,01 mg/L. Os pesquisadores Dantas e Apolinário (2014) encontraram resultados entre 5,0 a $9,3 \mathrm{mg} / \mathrm{L}$ para o oxigênio dissolvido na água em tanques rede.

$\mathrm{O}$ fato é que a tilápia $O$. niloticus consegue sobreviver com uma disponibilidade de água em torno de $1,2 \mathrm{mg} / \mathrm{L}$, pois a espécie tem uma boa resistência e adaptabilidade as variações bruscas na qualidade da água (FERREIRA et al., 2011).

A concentração de amônia total alcançou uma média de 2,09 mg/L de $\mathrm{NH}_{3}$ (Tabela 2), sendo considerado um ótimo valor para cultivo de tilápia em tanque escavado (KUBITZA, 2017). Ainda segundo o autor é comum encontrar valores de amônia total em viveiros escavados em torno de 4 a $6 \mathrm{mg} / \mathrm{L}$, não sendo o recomendável, mas tolerado pela espécie. O pesquisador relata que o maior valor de amônia total encontrado em suas pesquisas foi de $12 \mathrm{mg} / \mathrm{L}$. Já Vicentin et al. (2014) em seu trabalho "Monitoramento da amônia total, do nitrito e do nitrato em viveiros de piscicultura no Alto Vale do Itajaí" relata resultados de até $2,60 \mathrm{mg} / \mathrm{L}$ de amônia total.

Durante todo o período de cultivo os resultados obtidos nas análises mostram que o Nitrito presente na água dos viveiros escavados está dentro dos padrões de qualidade para uma boa criação, pois nenhum resultado, ultrapassou $0,3 \mathrm{mg} / \mathrm{L}$ de $\mathrm{NO}_{2}$ (Tabela 2).

De acordo com o Kit de análises da Acqua Supre os valores de $\mathrm{NO}_{2}$ não devem ultrapassar $1 \mathrm{mg} / \mathrm{L}$, já o "Manual de qualidade da água para aquicultura" de Oliveira (2000), estípula valores com máxima de $0,5 \mathrm{mg} / \mathrm{L}$ sendo que acima de $2,5 \mathrm{mg} / \mathrm{L}$ é letal para os animais. De um modo geral, a média alcançada nessa pesquisa para o nitrito é de $0,2 \mathrm{mg} / \mathrm{L}$ de $\mathrm{NO}_{2}$. Valores similares foram encontrados por Ferreira et al. (2016) no seu trabalho "Probiótico na alimentação de tilápias cultivadas em efluentes de esgotos doméstico tratado" com valores de nitrito com em torno de 0,7 a 2,0 mg/L. Já Silva (2016) no seu trabalho "Desenvolvimento e avaliação preliminar de sistema aquapônico com Bioflocos" relata valores de nitrito com média de $0,70 \mathrm{mg} / \mathrm{L}$.

Os resultados para $\mathrm{CO}^{2}$ dissolvido na água durante a pesquisa alcançou uma média de 17,02 $\mathrm{mg} / \mathrm{L}$ (Tabela 2). Esse valor é considerado excelente para a produção da tilápia, pois segundo (KUBTIZA, 1998; MERCANTE et al., 2007) os valores considerados ótimos para a piscicultura deve ser abaixo de $25 \mathrm{mg} / \mathrm{L}$ e, de acordo com (LEITE, 2009) em seu trabalho "Utilização de microrganismos eficazes como probiótico no cultivo da tilápia do nilo" resultados em torno de $23 \mathrm{mg} / \mathrm{L}$ de $\mathrm{CO}^{2}$ foram constatados.

De acordo com os dados apurados e resultados do $1^{\circ}$ Ciclo de Cultivo a Conversão Alimentar (CA) é em média $(1,12: 1)$, já valores de $(1,13: 1)$ foram encontrados por Ribeiro et al. (2010) para a tilápia da linhagem GIFT (Genetic Improved Farmed Tilapia) produzida em tanques escavados, mas para Munozet al. (2015) valores de (1,3:1) foram relatados para essa linhagem produzida em açudes na cidade de Assis Chateaubriand - Paraná, ainda segundo Carmo et al. (2008), de acordo com sua pesquisa na avaliação do crescimento de três linhagens de tilápia sob o cultivo semi-intensivo em viveiros, a linhagem chitralada apresenta um desempenho de CA de $(1,14: 1)$, sendo considerada de ótima qualidade.

No segundo ciclo de cultivo decorrente entre os meses de Outubro/2016 a Abril/2017, com dados referentes à (Tabela 2), a média de CA supera o ciclo anterior, pois foi alcançado o resultado de (0,87:1), logo: utilizou-se menos de $1 \mathrm{Kg}$ de ração para produzir $1 \mathrm{Kg}$ de biomassa. Dados os resultados apurados Rauh (2015) relata valores de redução na CA após adicionar substrato de perifíton, culminando em resultados de 1,42:1. Apesar dessa diferença, os resultados alcançados na presente pesquisa constatam valores satisfatórios, fortalecendo a base para uma boa produtividade e lucro. Segundo Faria et al. (2013) \& Sebrae (2014), 
os valores para CA devem ser menores que 1,5:1 para tilápia.

Em ambos os ciclos o resultado esperado foi alcançado, ou seja, uma despesca com média $700 \mathrm{~g}$ por animal, valor este requisitado pelo consumidor.

A criação em tanques escavados é uma alternativa em contrapartida a pesca extrativa, que ao longo dos anos acarretou diversos impactos ambientais, promovendo o desequilíbrio entre as espécies.

Com relação às vantagens da criação em tanques escavados podemos citar a facilidade de controle, monitoramento e manejo do cultivo, maior facilidade no processo de despesca e boa movimentação da água nos viveiros propiciando uma melhor oxigenação da água.

Esse trabalho abre portas para o agronegócio, comunidade cientifica e todos aqueles cujo o objetivo e se aprimorar na área agropecuária.

\section{CONCLUSÃO}

Através dos resultados expostos é possível concluir que os valores para os parâmetros físicos e químicos se mantiveram dentro dos padrões recomendados segundo a literatura estudada. $\mathrm{O}$ peso dos peixes obtidos após a despesca alcançou o valor exigido pelo consumidor local, com uma média de $700 \mathrm{~g}$ por animal. O custo de produção e tempo rendou boa produtividade, compensando os gastos e resultando em lucro significativo, sendo que a espécie $O$. niloticus apresentou boa adaptação as condições impostas pelo meio ambiente, tendo em vista que após a despesca a relação: consumo de ração $\mathrm{x}$ ganho de peso, recompensa o tempo de cultivo, o que reflete em produtividade

O cultivo da tilápia $O$. niloticus em tanque escavado se mostrou uma alternativa viável para o desenvolvimento sustentável e fonte de renda. O que vem a ressaltar sua importância no incremento da balança comercial nacional, pois esse estudo abrange produtores, extensionistas, pesquisadores e todos aqueles que almejam o interesse pela área.

Por fim, conclui-se que essa temática na área da piscicultura, abrange perspectivas de estudos futuros, sejam eles em tanques escavados, tanque rede, racewey, sistema de cultivo intensivo, semiintensivo e extensivo, reforçando cada vez mais a importância da tilapicultura no cenário econômico e nutricional.

\section{REFERÊNCIAS}

ABRUNHOSA, F. Técnico em Aquicultura: Piscicultura. Belém - PA: Instituto Federal de Educação, Ciência, e Tecnologia - IFPA, 2011. 133 f. Disponível em: < http://redeetec.mec.gov.br/images/stories/pdf/eixo_rec_na turais/aquicultura/181012_piscicult.pdf >. Acesso em: 10/08/2016.
APOLINÁRIO, M. O.; BELMINO, J. F. B.; SILVA, L. O.; DANTAS, M. B. ICTIOLOGIA E PISCICULTURA NO CURIMATAÚ PARAIBANO: Aspectos socioeconômicos, educativos e produtivos. $1^{\mathrm{a}}$ ed. Campina Grande: EDUFCG, 120 p. 2015.

ARAÚJO R.; MORAES, A. J. N. Diagnóstico da piscicultura nos municípios de Bocaina e Sussuapara Piauí. In: Simpósio de Produção Científica e Seminário de Iniciação Científica da UESPI, 10, 2010. Anais eletrônico. Teresina, PI: [s.n.], 2010. 16 p. Disponível em: <http://www.uespi.br/prop/siteantigo/XSIMPOSIO/TRA BALHOS/INICIACAO/Ciencias\%20Agrarias/DIAGNOS TICO\%20DA\%20PISCICULTURA\%20NOS\%20MUNI CIPIOS\%20DE\%20BOCAINA\%20E\%20SUSSUAPAR A-PIAUI.pdf>. Acesso em: 11/09/2017.

BARBOSA, A.C.; FERREIRA, P. M. F.; SOUZA, R.N.; BARBOSA, J.M. Avaliação da taxa metabólica do tambaqui (Colossoma macropomum) e da tilápia-do-nilo (Oreochromis niloticus). Revista Brasileira de Engenharia de Pesca, Pernambuco, v. 4, n. 2, p. 46-55. 2009.

BARbOSA, A. C. A.; MOURA, E. V.; SANTOS, R. V. Cultivo de tilápias em gaiolas. EMPARN, Natal, v. 17, 2010. 33 p.

BARROSO, R. M.; TENÓRIO, R. A; PEDROZA FILHO, M. X.; WEBBER, D. C.; BELCHIOR, L. S.; TAHIM, E. F.; CARMO, F. J.; MUEHLMANN, L. D. 2015. Gerenciamento genético da tilápia nos cultivos comerciais. Embrapa Pesca e Aquicultura. Palmas, TO. Série Documentos, v. 23. 64p.

BOCCAlETTO, E. M. A.; MENDES, R. T. (Org.). Alimentação, atividade física e qualidade de vidados escolares do Município de Vinhedo/SP. Campinas: IPES Editorial, 2009. Disponível em: $<$ http://www.bibliotecadigital.unicamp.br/document/?cod e=000468112 $>$. Acesso em: 12/09/2017.

CARMO, J. L.; FERREIRA, D. A.; SILVA JUNIOR, F. R.; SANTOS, R. M. S.; CORREIA, E. S. Crescimento de três linhagens de tilápia sob cultivo semi-intensivo em viveiros. Revista Caatinga. Mossoró. v. 21, n. 2, p. 2026, 2008.

CASTELLANI, D.; ABIMORAD, E. G.; MARQUES, H. L. A.; ROMERA, D. M.; GARCIA, F.; SCHALCH, S. H. C.; BOOCK, M. V. 2011. Policultivo de tilápias e camarão da Malásia no inverno: estudo de caso no noroeste paulista. In: X REUNIÃO CIENTÍFICA DO INSTITUTO DE PESCA, São Paulo, 07-08 dez. Resumos, p. 18-20. Disponível em:<ftp://ftp.sp.gov.br/ftppesca/10recip/resumos/X_ReCI P_R1_18-20.pdf>. Acesso em: 11/09/2017.

COMARELLA, R. Monitoramento do crescimento da tilápia do Nilo (Oreochromis niloticus). 2014. $35 \mathrm{f}$. Monografia (Graduação em Tecnologia de Aquicultura) Universidade Federal do Paraná, Palotina - PR, 2014. 
CAVALCANTE, D. H.; SILVA, S.R.; PINHEIRO, P. D.; AKAO, M. M. F.; SÁ, M. V. C. Single orpaired increase of total alkalinity and hardness of water for cultivation of Nile tilapia juveniles, Oreochromis niloticus. Acta Scientarium Technology, Maringá, v. 34, n. 2, p. 177 183. 2012.

DANTAS, M. B.; SILVA, L. O.; APOLINÁRIO, M. O. Variação temporal dos parâmetros físicos e químicos da água de cultivo de tilápia em tanques-rede no Açude Boqueirão do Cais, Cuité - PB. In: APOLINÁRIO, M. O.; BELMINO, J. F. B.; SILVA, L. O.; DANTAS, M. B. (Org.). Ictiologia e piscicultura no curimataú paraibano: aspectos socioeconômicos, educacionais e produtivos. Campina Grande: EDUFCG, p. 69-84. 2015.

DANTAS, J. R.; APOLINÁRIO, M. O. Otimização do cultivo de tilápias Oreochromis niloticus (linhagem chitralada) em sistema de tanques-rede no açude boqueirão do cais, cuité-pb. XI CONGRESSO DE INICIAÇÃO CIENTÍFICA DA UNIVERSIDADE FEDERÁL DE CAMPINA GRANDE, 03, 04 e 05 de Nov. Universidade Federal de Campina Grande, 2014. Disponível

em:

<http://pesquisa.ufcg.edu.br/anais/2014/resumos/xicicufc g_2406.pdf>. Acesso em: 10/09/2017.

DANTAS. M. B. CARACTERIZAÇÃO TEMPORAL DAS VARIÁVEIS FÍSICO-QUÍMICAS DO AÇUDE BOQUEIRÃO DO CAIS (CUITÉ - PB), NO CULTIVO EM TANQUES-REDE DA TILÁPIA Oreochromis niloticus. 2013. 38 f. Monografia de Conclusão de Curso (Curso de Licenciatura em Ciências Biológicas) - Universidade Federal de Campina Grande, 2013.

DIAS-NETO, J. Pesca no Brasil e seus aspectos institucionais - um registro para o futuro. Revista CEPSUL - Biodiversidade e Conservação Marinha, v. 1, n. 1, p. 66-80, 2010.

DUARTE, E.; MOREIRA, F. C.; PEDREIRA, M. M.; PIRES, A. V.Parâmetros físico-químicos da água para cultivo de tilápia do Nilo em sistemas de biofiltros. Boletim Técnico PPGZOO UFVJM, Diamantina - MG, v.2, n.2, p. 5-16, Junho/2014.

FAO - Food and Agriculture Organization of the United Nations.El estado mundial de la pesca y laacuicultura.Roma: FAO, 2009. 196p.

FARIA, R. H. S.; MORAIS, M.; SORANNA, M. R. G. S.; SALLUM, B. W. Manual de criação de peixes em viveiro. Brasília: Codevasf, 2013.

FERREIRA, P. M. F.; BARBOSA, J. M.; SANTOS, E. L.; SOUZA, R. N.; SOUZA, S. R. Avaliação do consumo de oxigênio da tilápia do Nilo submetidas a diferentes estressores. Revista Brasileira de Engenharia de Pesca, v. 6, n. 1, p. 56-62, 2011.
FERNANDES, A. S. Amostragem de Ectoparasitos de Tilápia do Nilo Oreochromis niloticus (Linnaeus, 1758) em cultivo comercial. 2014. 32f. Trabalho de Conclusão de Curso Monografia (Bacharel em Engenharia de Aquicultura) - Universidade Federal de Santa Catarina. Centro de Ciências Agrárias. Curso de Engenharia de Aquicultura. 2014.

FERRAZ, D. R.; AMARAL, A. A. Variação nictemeral dos parâmetros físico-químicos da água de um viveiro de cultivo de tilápia. XIV Encontro Latino Americano de Iniciação Científica e $X$ Encontro Latino Americano de Pós-Graduação, 21 - 22 de out., Universidade do Vale do Paraíba, 2010. Disponível em: < http://www.inicepg.univap.br/cd/INIC_2010/anais/arquiv os/0911_0976_01.pdf >. Acesso em: 12/09/2017.

FITZSIMMONS, K. Market stability: Why Tilapia supply and demand have avoided the boom and busts of other commodities. 4th International Trade and Technical Conference and position on Tilapia. Kuala Lumpur, Malaysia. 2015.

GARCIA, C. A. B.; SANTOS, G. P.; GARCIA, H. L. Análise dos parâmetros físico-químicos dos viveiros de camarão na grande Aracaju - Sergipe. Revista Ciências Exatas e Naturais (Impresso), v. 11, p. 209-225, 2009.

GRAEF, A.; TOMAZON, A. F.; NAZARENO, P. E.; MARAFON, T. A. Influência da dureza e do $\mathrm{pH}$ no desenvolvimento do Jundiá (Rhamdia quelen) na fase de fertilização até a produção de póslarvas. REDVET, v. 8, p. 339-347, 2007.

GUIMALHÃES, A.F. Criação de peixes. Ilhéus - BA. Ceplac. 28p. 2012.

HENRY-SILVA, G. G.; CAMARGO, A. F. M. Impacto das atividades de piscicultura e sistemas de tratamento de efluentes com macrófitas aquáticas - relato de caso. Boletim do Instituto de Pesca, São Paulo, v. 34, n. 1, p. 163-173. 2008.

INSTITUTO BRASILEIRO DE GEOGRAFIA E ESTATÍSTICA - IBGE. Produção Pecuária Municipal, Rio de Janeiro - RJ, v. 42, 39 p. 2014.

KOCHE, I. Implantação de um sistema semi-intensivo de piscicultura como alternativa de renda em uma propriedade rural. 2013. 20 f. Projeto apresentado ao Curso de Graduação de Ciências Rurais. Universidade Federal de Santa Catarina -(UFSC), Campus Curitibanos, Santa Catarina SC - UFSC, 2013.

KUBITZA, F. Qualidade da água: no cultivo de peixes e camarões. $1^{a}$ ed. Jundiaí - SP. 2003, 208 p.

KUBITZA, F. Piscicultura em Rondônia: a força de um setor organizado. Revista Panorama da Aquicultura, v. 27, n. 160, p. 3-66, março/abril, 2017. 
KUBITZA, F. Produção de tilápias em tanques de terra: estratégias avançadas no manejo. Revista Panorama da aquicultura, v. 19, n. 115, p. 15-21, set./out. 2009.

KUBITZA, F. Qualidade da água na produção de peixes. Parte II. Revista Panorama da Aquicultura, v. 8, n. 46, p. 36-41, 1998.

LANDELL, M. C. Avaliação do desempenho de tilápias (Oreochromis niloticus, Trewavas, 1983) em tanquesrede na represa de Jurumirim/Alto Rio Paranapanema. 2007. 106 f. Dissertação (Mestrado em Aquicultura), Centro de Aquicultura, Universidade Estadual Paulista, Jaboticabal, 2007.

LEIRA, M. H.; CUNHA, L. T.; BRAZ, M. S.; MELO, C. C. V.; BOTELHO, H. A.; REGHIM, L. S. Qualidade da água e seu uso em pisciculturas. PUBVET, v. 11, n. 1, p. 11-17, jan. 2017. Disponível em: <http://www.pubvet.com.br/artigo/3588/qualidade-daaacutegua-e-seu-uso-em-pisciculturas $>$. Acesso em: 20 fev. 2017.

\section{LEITE, M. J. C. UTILIZAÇÃO DE MICROORGANISMOS EFICAZES COMO PROBIOTICO NO CULTIVO DA TILAPIA DO NILO. 2009. 51 f. Dissertação (Mestre em Zootecnia) - Universidade Federal da Paraíba, Centro de Ciências Agrárias, Programa de Pós-Graduação em Zootecnia, Areia - PB, 2009.}

LIMA, A. F.; SILVA, A. P.; RODRIGUES, A. P. O.; BERGAMIN, G. T.; TORATI, L. S.; PEDROZA FILHO, M. X.; MACIEL, P. O. Qualidade da água: piscicultura familiar. Palmas: Embrapa Pesca e Aquicultura, 2013. 8p. Disponível em: < https://www.infoteca.cnptia.embrapa.br/bitstream/doc/97 2064/1/agua.pdf >. Acesso em: 12/01/2017.

LIMA, C. B.; OLIVEIRA, E. G.; ARAÚJO FILHO, J. M.; SANTOS, F. J. S.; PEREIRA, W. E. Qualidade da água em canais de irrigação com cultivo intensivo de tilápia nilótica (Oreochromis nilóticus). Revista Ciência Agronômica, v. 39, n. 4, p. 531-539, 2008.

MATA, D. A. É possível viver no semiárido. In: ARAÚJO, Vicente de Paulo Albuquerque (Org.). Pelos caminhos do Semiárido. Campina Grande: Eduepb, 2013. p. $157-160$.

MATA, D. A.; SANTOS, A. M. D.; SILVA, H. L. P.; DANTAS, M. B.; APOLINÁRIO, M. O. Implantação de um sistema de piscicultura em tanques escavados como alternativa de renda para piscicultores no Semiárido Paraibano. In: I Congresso Internacional da Diversidade do Semiárido, 11, 2016, Campina Grande PB. Anais eletrônico. I CONIDIS. Campina Grande - PB: Realize Eventos e Editora, 2016. v. 1. Disponível em: <http://www.editorarealize.com.br/revistas/conidis/tra balhos/TRABALHO_EV064_MD4_SA6_ID1893_21102 016192034.pdf>. Acesso em: 10/ 10/2017.
MPA - MINISTÉRIO DA PESCA E AQUICULTURA. BRASIL. Boletim estatístico da pesca e aquicultura. Brasília, 2012. 129 p.

MERCANTE, C. T. J.; SILVA, D.; COSTA, S. V. Avaliação da qualidade da água de pesqueiros na Região Metropolitana de São Paulo por meio do uso de variáveis abióticas e Clorofila. In: ESTEVES, K. E. e SANT'ANNA, C. L. (Org.) Pesqueiros sob uma visão integrada de meio ambiente, saúde pública e manejo: um estudo na Região Metropolitana de São Paulo. São Paulo. RiMa Editora. 2006. 240p.

MERCANTE, C. T. J.; MARTINS, K. Y.; CARMO, C. F.; OSTI, J. S.; MAINARDES - PINTO, C. S. R.; TUCCI, A. Qualidade da água em viveiro de Tilápia do Nilo (Oreochromis niloticus): caracterização diurna de variáveis físicas, químicas e biológicas, São Paulo, Brasil. Bioikos, v. 21, n. 2, p. 79-88. 2007.

MUNOZ, A. E. P.; FLORES, R. M. V.; PEDROZA FILHO, M. X.; BARROSO, R. M.; MATAVELI, M.; REZENDE, F. P. Tilapicultores e técnicos discutem custos de produção da aquicultura em Assis Chateaubriand. Palmas: Embrapa Pesca e Aquicultura, 2015. 6 p. (Informativo Campo Futuro, 10).

NETO, A. D. L.; FERREIRA, R. N. C.; BEZERRA, J. H. C.; PINTO, C. R. S.; LEITE, M. B.; MARQUES, C. H. P.; FACUNDO, G. M.; COSTA, J. M. Criação de peixes em viveiros escavados. Fortaleza - CE. 2016. 69 p.

OLIVEIRA, E. G.; SANTOS, F. J. S. Piscicultura e os desafios de produzir em regiões com escassez de água. Revista Ciência Animal, v. 25, n. 1, p. 133-154, 2015.

OLIVEIRA, E.G.; SANTOS, F.J.S.; PEREIRA, A.M.L.; LIMA, C.B. Produção de tilápia: Mercado, espécie, biologia e recria. Circular Técnica, v. 45, n. 12, p. 1-12. 2007.

OLIVEIRA, R. P. C.; SILVA, P. C.; BRITO, P. P.; GOMES, J. P.; SILVA, R. F.; SILVEIRA FILHO, P. R.; ROQUE, R. S. Variáveis hidrológicas físico-químicas na criação da tilápia do Nilo no Sistema Raceway com diferentes renovações de água. Revista Ciência Animal Brasileira, Goiânia, v. 11, n. 3, p. 482-487, jul./set. 2010.

OLIVEIRA, L. Manual de qualidade da água para aquicultura. Florianópolis - SC: [s.n.], 2000

OLIVEIRA, R.C. O panorama da aqüicultura no Brasil: a prática com foco na sustentabilidade Revista Intertox de Toxicologia, Risco Ambiental e Sociedade, v. 2, n. 1, fev. 2009.

POPMA, T.; MASSER, M. Tilapia Life story and biology. Southern regional aquaculture Center (SRAC). Publication $\mathrm{n}^{\circ}$ 283. March, 1999. Disponível em: <http://www2.ca.uky.edu/wkrec/tilapiabiologyhistory.pdf $>$. Acessado em: 20/09/2016. 
RAUH, G. Crescimento da tilápia (Oreochromis niloticus, linnaeus 1758) e qualidade da água: efeito do perifíton. 2015. 43 f. Trabalho de Conclusão de Curso (Monografia em Engenharia de Aquicultura) Universidade Federal de Santa Catarina, Centro de Ciências Agrárias, Departamento de Aquicultura, Curso de Engenharia de Aquicultura, 2015.

RIBEIRO, L.G; GARCÍA, S.; SCHWINGEL, P. R.; AMARAL JÚNIOR, H.; Mello, G. L.; PASCO, J. M.; SILVA, F. M. Desenvolvimento da tilápia GIFT Oreochromis niloticus em diferentes densidades de cultivo no litoral norte do estado de Santa Catarina. In: IV Congresso Brasileiro de Oceanografía. 05. 2010, Rio Grande - RS. Anais do IV Congresso Brasileiro de Oceanografia, 2010.2 Disponível em:<http://intranetdoc.epagri.sc.gov.br/producao_tecnico _cientifica/DOC_26831.pdf>. Acessado em: 04/07/2016.

ROSSI, V. G. A utilização da tecnologia de bioflocos (TBF) na piscicultura: histórico e principais técnicas de manejo de sistema. 2014. 45 f. Trabalho de Conclusão de Curso (Graduação em Medicina Veterinária). Universidade Federal do Rio Grande do Sul/UFRGS, Porto Alegre, 2014.

ROSA, J.; NOLETO, R. B.; RIBEIRO, M. O. Avaliação do efeito substitutivo de ração por adubação orgânica na alimentação em alevinos de tilápia (Oreochromis niloticus). Revista Luminária (União da Vitória), v. 16, p. 119-130, 2014.

SAMPAIO, J. Multiplicar os peixes. AgroANALYSIS, São Paulo, V.30, n. 2, p. 50, Fev. 2010. Disponível em: <http://bibliotecadigital.fgv.br/ojs/index.php/agroanalysis/ article/view/26477/25334>. Acessado em: 20 de jan. 2017.

SARAIVA, K. A.; MELO, F. P.; APOLINÁRIO, M. O.; SANTOS, A. J. G.; CORREIA, E. S. Densidades de estocagem de juvenis da tilápia Oreochromis niloticus (linhagem Chitralada) cultivados em tanques-rede. Revista Brasileira de Saúde e Produção Animal, v. 10, n. 4, p. 963-969, 2009.

SANTOS, M. M.; CALUMBY, J. A.; COELHO FILHO, P. A.; SOARES, E. C.; GENTELINI, A. L. NÍVEL DE ARRAÇOAMENTO E FREQUÊNCIA ALIMENTAR NO DESEMPENHO DE ALEVINOS DE TILÁPIA-DONILO. Boletim do Instituto de Pesca (Impresso), v. 41, p. 387-395, 2015.

SAVITISKY, J. A. Avaliação do consumo de fontes de proteína de origem animal empré-escolares. 2013. 66p. Dissertação (Mestrado em Produção Animal Sustentável) - Instituto de Zootecnia. APTA/SAA. Nova Odessa, 2013.

SEBRAE - RN- Serviço de Apoio às Micro e Pequenas Empresas do Rio Grande do Norte. Criação de tilápia em tanques escavados. - Natal: SEBRAE/RN, 2014. 32 p. Disponível em: <http://www.bibliotecas.sebrae.com.br/chronus/ARQUIV OS_CHRONUS/bds/bds.nsf/8f207413cf7a8402b142400d 385397ad/\$File/5203.pdf>. Acesso em: 02/07/2016.
SIDONIO, L.; CAVALCANTI, I.; CAPANEMA, L.; MORCH, R.; MAGALHÃES, G.; LIMA, J.; BURNS, V.; ALVES JÚNIOR, A .J.; MUNGIOLI, R. Panorama da aquicultura no Brasil: desafios e oportunidades. BNDES Setorial, v. 35, p. 421-463, 2012.

SILVA, G. C. Limnologia de viveiros escavados da base de piscicultura Carlos Eduardo Matiazze. 2014. 56 f. Trabalho de conclusão de curso (Monografia) Engenharia de Pesca, Fundação Universidade Federal de Rondônia, Departamento de Engenharia de Pesca, Presidente Médici, Rondônia, 2014.

SILVA, P. R. D. Desenvolvimento e avaliação preliminar de sistema aquapônico com Bioflocos. 2014. 49 f. Dissertação (Mestrado em Ciência e Tecnologia de Alimentos) - Instituto Federal de Educação, Ciência e Tecnologia do Triângulo Mineiro, Uberaba, 2016.

USHIZIMA, T. S. Manual de boas práticas de produção em piscicultura. Departamento de Pesquisa e Desenvolvimento em Aquacultura Nutrizon Alimento LTDA. Manaus - AM: NUTRIZON FILIAL MANAUS, 2016, 49 p. Disponível em:<http://nutrizon.com.br/files/Manual_BPP.pdf>.

Acesso em: 07/10/2016.

VICENTIN, E.; SCHMOELLER, J. R.; MAXIMO, B.; FEUZER, C.; VOSS, E.; MULLER, I. C.; JUBINI, G.; HERMES, C. A. Monitoramento da amônia total, do nitrito e do nitrato em viveiros de piscicultura no Alto Vale do Itajaí. Nov. 2014. In: XV Feira de Tecnologias, Engenharias e Ciências - FETEC. nov. 2014, Santa Catariana. Anais Eletrônico. Instituto Federal Catarinense - IFC, Araquari - SC. 2014. Disponível em:<https://ocs.araquari.ifc.edu.br/index.php/micti/micti2 014/paper/viewFile/343/110>. Acessado em: 12/9/2016

VIDAL, M. F. Panorama da piscicultura no Nordeste. Fortaleza - CE. Caderno Setorial ETENE. v. 1. n. 3. Nov.2016.

WAMBACH, X. F. Manejo Prático Aplicado a Piscicultura de Água Doce. 2012. 28 f. Dissertação (Mestrado em Recursos Pesqueiros e Aquicultura) Universidade Federal Rural de Pernambuco, Departamento de Zootecnia, Recife - PE, 2012. 